\title{
Orbital wall thickness and the spread of infection from the paranasal sinuses
}

\author{
R. P. MILLS AND J. M. KARTUSH \\ Department of Otolaryngology, Head and Neck Surgery, University of Michigan Medical School, \\ Ann Arbor, Michigan, USA.
}

Accepted for publication 25 April 1985

Mills R. P. \& Kartush J. M. (1985) Clin. Otolaryngol. 10, 209-216

\begin{abstract}
Orbital wall thickness and the spread of infection from the paranasal sinuses
Ninety-three human skulls ( 80 adults and 13 children) have been examined and the extent of thin bone in the party walls between the orbit and the frontal, ethmoidal and maxillary sinuses has been assessed. Translucent bone is most often present in the lateral wall of the ethmoidal labyrinth and least often in the floor of the frontal sinus. In children such bone is present significantly less often in the roof of the maxillary sinus $(P<0.001)$ than in adults. Computerized tomography scans and clinical data from 6 patients with orbital cellulitis were reviewed. In one of these an inferolateral subperiosteal abscess of the orbit was associated with a defect in the roof of the maxillary sinus. Two patients had a medial subperiosteal abscess associated with ethmoiditis and in one there was direct continuity between the abscess and the adjacent ethmoidal cells. In another case a superolateral abscess was demonstrated in continuity with a surgical defect in the floor of the frontal sinus. We conclude that the ethmoidal, frontal or maxillary sinuses may be sources of orbital infection and that spread occurs either by direct extension through the sinus wall or by local thrombophlebitis.
\end{abstract}

Keywords sinusitis orbital cellulitis pathogenesis

Orbital cellulitis forms part of a spectrum of orbital and periorbital sepsis. Periorbital or preseptal cellulitis is oedema or cellulitis of the eyelids superficial to the orbital septum. It is a more common condition than true orbital cellulitis ${ }^{1}$ and frequently arises as a result of sources of infection other than sinusitis. ${ }^{2}$ The term 'orbital cellulitis' encompasses diffuse cellulitis of the orbital contents, subperiosteal abscess of the orbit and orbital abscess. This latter condition may result from rupture of a subperiosteal abscess or coalescence of diffuse orbital infection. ${ }^{3-6}$ Extension of infection posteriorly may result in cavernous sinus thrombosis with development of signs in the other eye.
There appears to be disagreement about which sinus is most commonly the source of infection in orbital cellulitis. Montgomery ${ }^{7}$ states that the ethmoidal air cells are the most common origin. According to Clairmont and Per-Lea ${ }^{8}$ the ethmoidal and sphenoidal sinuses are responsible, with or without concommitant frontal sinusitis. Dawes $^{9}$ agrees that ethmoiditis is associated with this complication in children, but considers frontal sinusitis most commonly implicated in adults. $\mathrm{He}$ states that the maxillary sinus is rarely a source of orbital infection. An examination of published series of cases of orbital cellulitis due to infected sinuses ${ }^{3,} 10-16$ indicates even wider variation of opinion

Correspondence: Mr R. P. Mills, ENT Department, King's College Hospital, Denmark Hill, London SE5 9RS. 
(Table I). These differences can probably be explained on the basis of age differences in the groups studied and variations in radiological techniques and interpretation of films. The assessment of patients with orbital infection has been improved in recent years with the introduction of computerized tomography (CT) scanning. . $^{47,18}$

The purpose of the present study was to clarify the role of individual sinuses in the pathogenesis of orbital infection and the routes by which spread occurs.

\section{Materials and methods}

Data has been collected from two different sources.

\section{AN ANATOMICAL STUDY OF THE}

THICKNESS OF THE ORBITAL WALLS

Ninety-three human skulls were examined and the extent of thin bone in the party walls between the orbit and the frontal sinus, ethmoidal labyrinth and maxillary antrum was assessed. 'Thin bone' was defined as bone having a similar translucent appearance to the typical bone of the lamina papyracea. In addition to simple inspection, transillumination was employed to aid the identification of areas of this type of bone. All specimens were examined by one observer (RPM). In a minority of cases, there were differences between the findings on the two sides. Therefore, the results have been expressed in terms of numbers of orbits rather than skulls. Each orbital wall was classified into one of four groups.

1 No thin bone

2 Limited area of thin bone

3 Moderate area of thin bone

4 Extensive thin bone

\section{A RETROSPECTIVE STUDY OF CASES OF ORBITAL CELLULITIS}

CT scans from patients with orbital cellulitis treated at the University of Michigan were reviewed without reference to the patients previous medical records. Both authors examined the films to determine which sinuses showed evidence of infection and whether or not there were signs of abscess formation within the orbit. All films used in the study were taken using a General Electric 8800 CT Scanner. Once the radiographic findings were recorded, the case notes were reviewed to see if the appearance on CT scanning could be confirmed by the clinical course of the disease or by operative findings.

\section{Results}

Of the 93 skulls examined, 80 were normal adult specimens used in routine teaching in

Table 1 Involved sinuses in reported cases of orbital cellulitis

\begin{tabular}{|c|c|c|c|c|c|c|c|c|c|}
\hline \multirow[b]{2}{*}{ Author } & \multirow[b]{2}{*}{ Date } & \multirow[b]{2}{*}{ Cases } & \multicolumn{7}{|c|}{ Involved sinuses (\%) } \\
\hline & & & Ethr & hmoid Antrum & Frontal & $\begin{array}{l}\text { Ethmoid } \\
\text { \& antrum }\end{array}$ & $\begin{array}{l}\text { Frontal } \\
\& \text { ethmoid }\end{array}$ & $\begin{array}{l}\text { Antrum } \\
\& \& \text { frontal }\end{array}$ & Pansinusitis \\
\hline Gamble & 1933 & 21 & 71 & 19 & 5 & 5 & 0 & 0 & 0 \\
\hline Birch-Hirschfield, & 1933 & 684 & 21 & 22 & 29 & 0 & 0 & 0 & 15 \\
\hline Haynes \& Cramblett* & 1967 & 26 & $\begin{array}{r}21 \\
8\end{array}$ & $\begin{array}{r}22 \\
0\end{array}$ & 0 & 77 & $\mathbf{0}$ & 0 & $\begin{array}{r}15 \\
4\end{array}$ \\
\hline Jarrett \& Guttman & 1969 & 7 & 14 & 0 & 0 & 0 & 29 & 14 & 43 \\
\hline Quick \& Payne & 1972 & 12 & 9 & 18 & 9 & 36 & 9 & 0 & 27 \\
\hline Gans et al. & 1974 & 120 & 6 & 42 & 8 & 6 & 4 & 0 & 33 \\
\hline Hawkins \& Clark* & 1977 & 24 & 0 & 0 & 0 & 62 & 29 & 0 & 8 \\
\hline Brook et al.* & 1980 & 8 & 12 & 0 & 25 & 50 & 0 & 0 & 12 \\
\hline Morgan \& Morrison & 1980 & 14 & 0 & 0 & 7 & 7 & 14 & 0 & 71 \\
\hline
\end{tabular}

*Children only 
Table 2 The extent of thin bone between the orbit and the paranasal sinuses in 80 adult skulls $(n=160$ orbits)

\begin{tabular}{lcccccc}
\hline Extent of & & & & & & \\
thin bone & Ethmoids & $\%$ & Frontal & $\%$ & Maxillary & $\%$ \\
1 None & 0 & 0 & 134 & 84 & 50 & 31 \\
2 Limited & 4 & 2.5 & 2 & 1 & 41 & 26 \\
3 Moderate & 34 & 21 & 6 & 4 & 41 & 26 \\
4 Extensive & 122 & 76 & 18 & 11 & 28 & 18 \\
\hline
\end{tabular}

the Anatomy Department at the University of Michigan. The results for this group are presented in Table 2. They reveal that translucent bone was most frequently present in the medial orbital wall, less often in the floor of the orbit and least often in the roof. The other 13 were children's skulls (ages 5-16 years) from the department's collection of skulls. Three of them showed evidence of hydrocephalus, but the remainder were normal. The results for this group are presented in Table 3 . In these skulls too, thin bone was very frequently present in the medial orbital wall. However it was seldom present in the roof or floor. The results for the 3 sinuses in adults and children were compared using a Chisquared test. There was a highly significant difference in the extent of thin bone in the roof of the maxillary antrum between the 2 groups $\left(\chi^{2}=27.6, \quad P=<0.001\right), \quad$ the children being less likely to have a significant area of thin bone. No difference was apparent between the two groups with regard to the medial orbital wall $\left(\chi^{2}=2.4\right.$, $P=>0.5$ ) or the floor of the frontal sinus $\left(\chi^{2}=7.3, P>0.05\right)$.

The same collection of skulls includes an example of congenital dehiscences of the orbital walls (Figure 1). Examination of this specimen revealed extensive deficiencies in the lateral and medial walls on both sides and of the floor on the right, allowing access to the orbit from both ethmoidal labyrinths and the right maxillary antrum.

CT scans from 6 patients with orbital cellulitis were reviewed, 4 male and 2 female, ranging in age from 8-55 years with a mean of 25.8 years. Five of these had radiological evidence of infection of one or more paranasal sinuses, but the other (case 5) did not. There was evidence of infection of the ethmoidal, frontal and maxillary sinuses but in no case was sphenoiditis demonstrated. The scans from cases 1 and 2 suggested superiorly placed subperiosteal abscesses of the orbit. Both had undergone previous frontoethmoidectomy operations and in case 2 surgical exploration confirmed the presence of a superolateral abscess in direct continuity with the frontal sinus via the surgical defect (Figure 3). The orbital cellulitis in case 1 resolved on medical treatment without surgery. Cases 3 and 4 had surgically confirmed medial subperiosteal abscesses of the orbit (Figures 4 and 6). In case 3 a defect in the lamina papyracea was noted at operation and there was direct continuity between the abscess and the infected ethmoidal cells. In

Table 3 The extent of thin bone between the orbit and paranasal sinuses in 13 skulls from children or adolescents ( $n=26$ orbits)

\begin{tabular}{lcrlrlr}
\hline $\begin{array}{l}\text { Extent of } \\
\text { thin bone }\end{array}$ & Ethmoids & $\%$ & Frontal & $\%$ & Maxillary & $\%$ \\
1 None & 0 & 0 & 23 & 88 & 22 & 84 \\
2 Limited & 2 & 7 & 2 & 8 & 2 & 8 \\
3 Moderate & 6 & 23 & 1 & 4 & 0 & 0 \\
4 Extensive & 18 & 70 & 0 & 0 & 2 & 8 \\
\hline
\end{tabular}




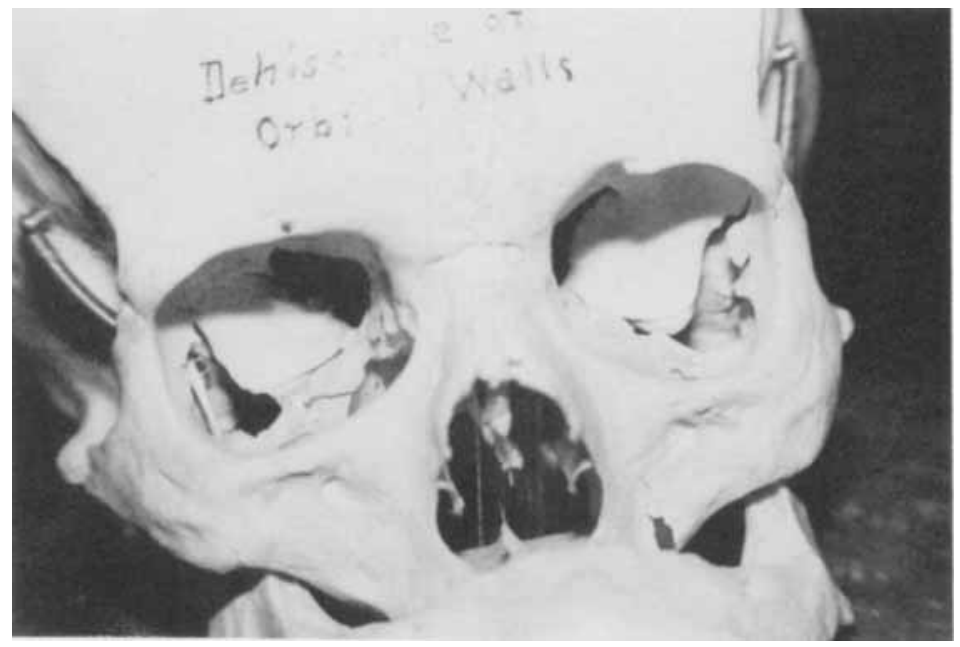

Figure 1 Skull with extensive dehiscences of the orbital walls on both sides.

case 6 the CT scan did not show evidence of intraorbital abscess formation, but did suggest infection of the soft tissues of the face. At operation an inferolateral subperiosteal abscess of the orbit was found communicating with the maxillary sinus via a defect in the orbital floor. Examples of the CT scans from the 6 patients are presented in Figures 2-7.

\section{Discussion}

There are 4 possible routes by which infection might pass between the paranasal

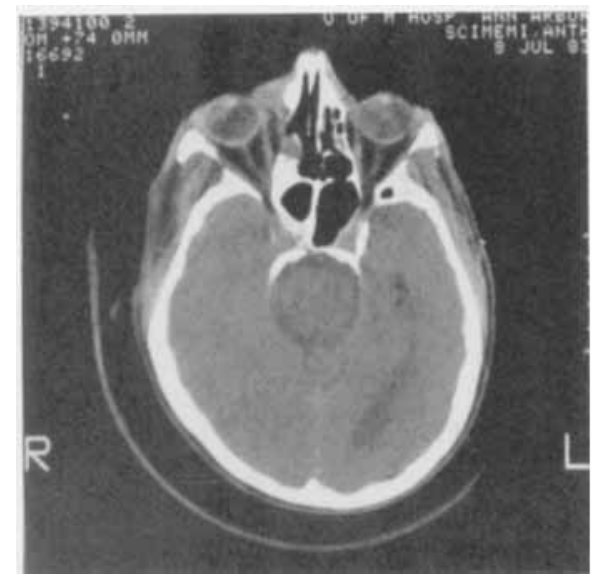

sinuses and the orbit: arteries, veins, lymphatics and direct extension through bone. Bacteraemia occurs in $15-17 \%$ of patients, ${ }^{2,19}$ and the general circulation is a more likely route for systemic rather than local spread. There are no known lymphatics within the orbit, although they are found in the eyelids and paranasal sinuses. $^{20-23}$

Venous connections exist between the maxillary, frontal and ethmoidal sinuses and the orbit. ${ }^{22}$ Venous pathways between the sphenoidal sinus and the orbit have also been reported. ${ }^{24}$ The vessels in this

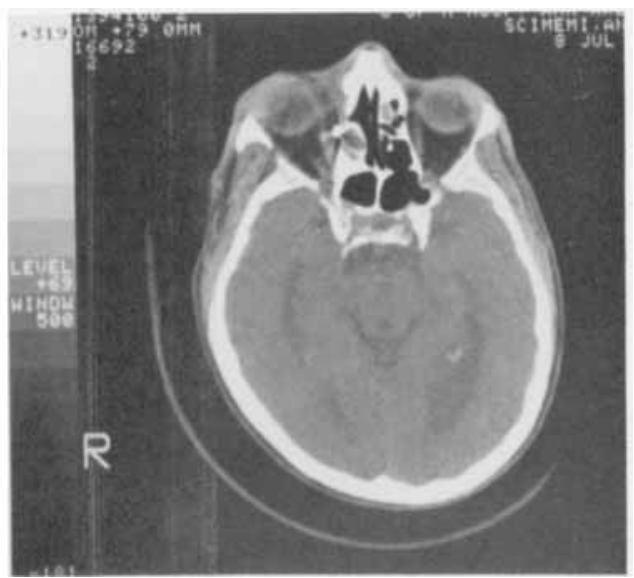

Figure 2. Case 1: CT scan showing opacification of posterior ethmoid cells on the right and of anterior and middle cells on the left. A surgical defect can be seen in the lateral wall of the right ethmoidal labyrinth and there is a clip on the anterior ethmoidal artery. There is an area of oedema in the anteromedial portion of the right orbit which is probably superficial to the orbital septum. 

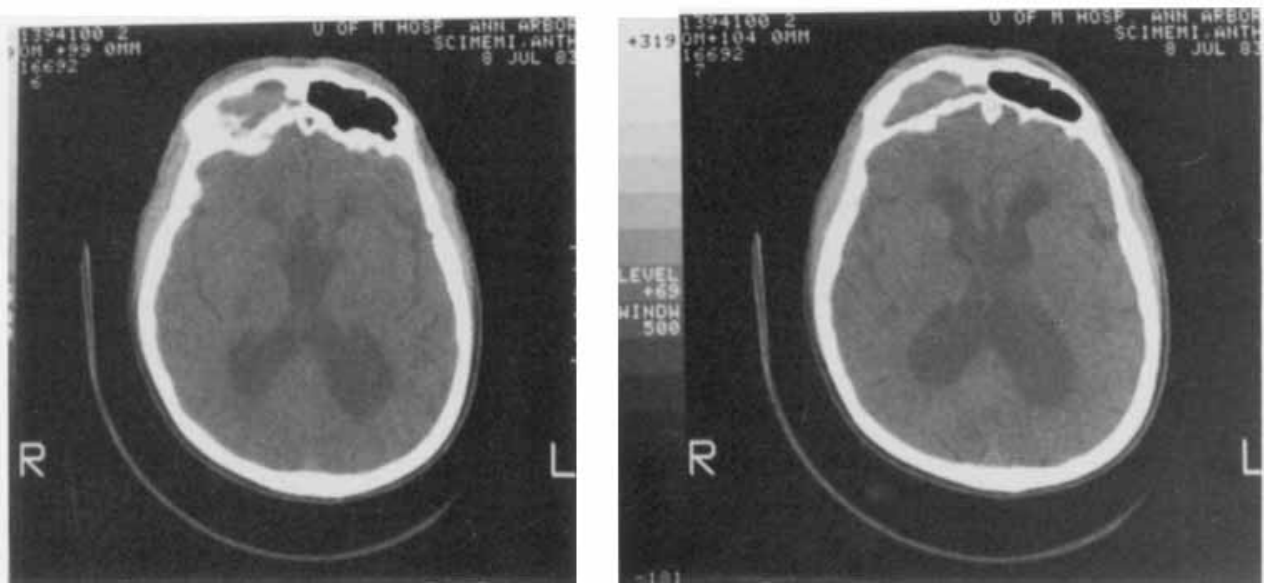

Figure 3. Case 1: CT scan showing opacification of the right frontal sinus.

area have no valves, and flow can therefore occur in either direction. ${ }^{22}$ According to Chandler $^{23}$ and Hajek ${ }^{24}$ septic thrombophlebitis is the most common means of spread of infection. Hajek ${ }^{24}$ has described cases in which septic thrombi were observed in the orbital venous systems of patients with orbital cellulitis at postmortem examination.

Our anatomical study confirms that thin

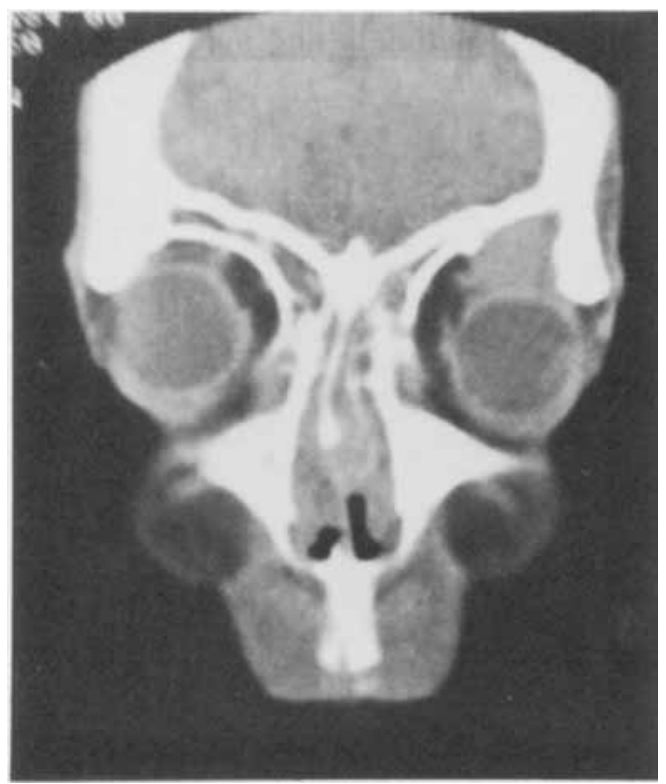

Figure 4. Case 2: CT scan showing a surgical defect in the floor of the left frontal sinus in continuity with a superolateral subperiosteal abscess of the orbit. bone is always present in the lamina papyracea as its name implies. In addition, there may be congenital dehiscences in the bone. ${ }^{25.26}$ The cellular structure of the ethmoidal labyrinth means that pus can accumulate under pressure adjacent to this partition and breach it. This is probably the most common way in which a subperiosteal abscess is produced. Most abscesses lie medially within the orbit. ${ }^{6,17}$ Both Harley \& Guerier ${ }^{5}$ and Jarrett \& Gutman $^{12}$ have described cases (similar to case 3 ) in which there was direct continuity

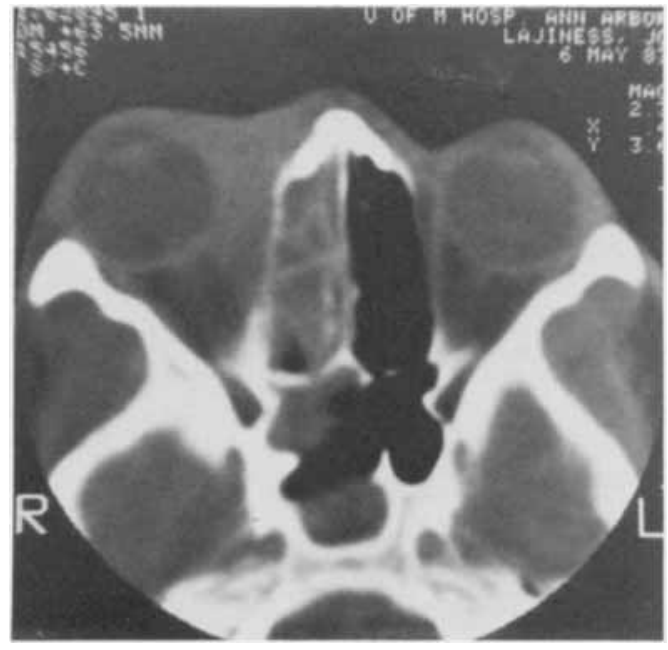

Figure 5 Case 3: CT scan showing opacification of the right ethmoidal labyrinth with an adjacent medial subperiosteal abscess of the orbit. 


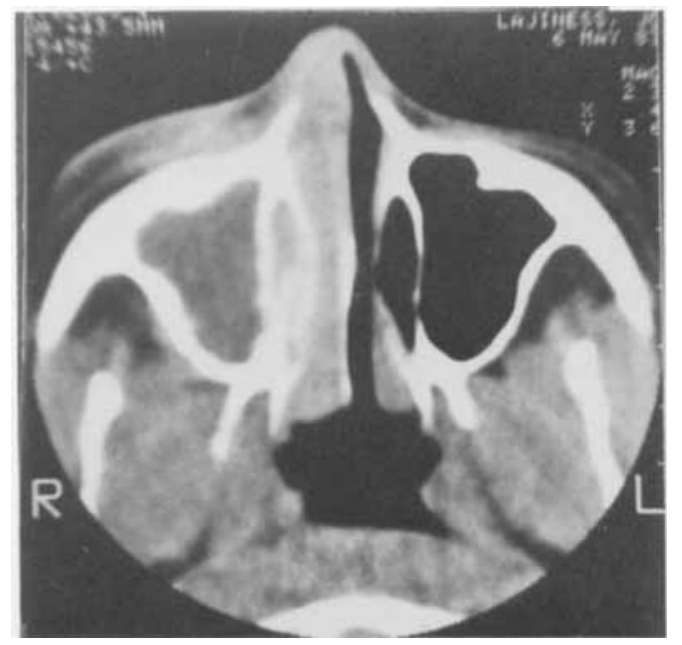

Figure 6 Case 3: CT scan showing opacification of the right maxillary sinus.

between pus in the ethmoidal labyrinth and an abscess via a defect in the lamina papyracea.

The frontal sinus is larger than an ethmoidal air cell and bone of comparable thickness to the lamina papyracea is not often present in its floor. However, the floor is usually the thinnest wall of the sinus $^{26,28}$ and osteitis is capable of producing defects in the anterior and posterior walls of the sinus leading to subperiosteal abscess formation in the forehead and

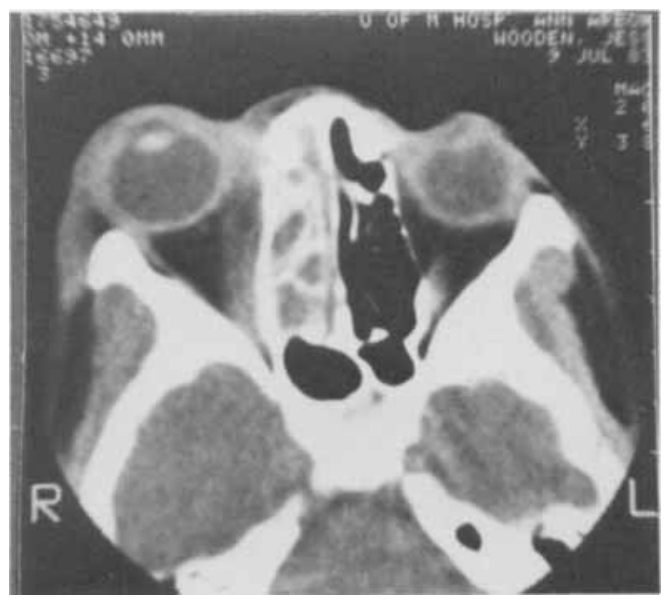

Figure 7 Case 4: CT scan showing opacification of the right ethmoidal labyrinth with an adjacent medial abscess of the orbit.

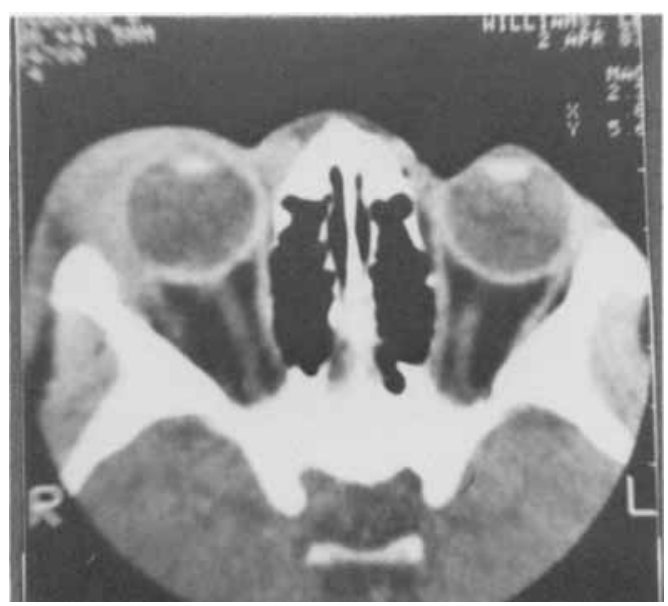

Figure 8 Case 5: CT scan showing a laterally placed area of pre- and post-septal cellulitis of the orbit.

cranial cavity. Abscesses in the superolateral part of the orbit have been previously described in which there was no history of previous frontal sinus surgery. ${ }^{6,18}$ Superomedial abscesses may arise either from the frontal or ethmoidal sinuses. Harris ${ }^{6}$ has reported a case in which an abscess was found in the orbit of a neonate with an infected intravenous infusion site, and without any evidence of sinusitis. This lesion must therefore have arisen as a result of a septic thrombophlebitis, and this in turn suggests that an actual break in the bone is not essential in every case. This is particularly relevant to the frontal sinus because unlike the other paranasal sinuses it is set in diploeic bone. $^{29}$

Pus within the maxillary antrum will only come into contact with the roof of the sinus if the sinus is full of infected material or when the patient lies down. By contrast pus in the frontal and ethmoid sinuses will be constantly in contact with the respective portions of the orbital wall. The volume of the maxillary antrum is about $15 \mathrm{ml}$ in the adult. ${ }^{26,27}$ The sinus is smaller in the child, but our data indicate that there is less likelihood of its roof being thin. Case 6 demonstrates that direct extension of infection from the maxillary sinus can occur, although it is rare in otherwise 
uncomplicated maxillary sinusitis. Sequestration of the orbital floor has been described in association with osteomyelitis of the maxilla. ${ }^{30}$

There were no cases of sphenoiditis evident on CT scanning in our series. None of the series of cases presented in Table I included any report of sphenoiditis, although this sinus may have been involved in cases described as 'pansinusitis'. Goldberg et al. ${ }^{17}$ reported 1 case in which opacification of the sphenoid sinus on CT scanning was associated with infection of the ethmoid and maxillary sinuses in a case of orbital cellulitis. If infection does spread from the sphenoid sinus to the orbit it is probably a very rare event.

In most of our cases there was close agreement between the CT appearance and the operative findings and clinical course of the disease. The main exception was case 6 . In this patient coronal cuts might have provided more accurate imaging.

We conclude that orbital subperiosteal abscess is a complication of ethmoidal, maxillary or frontal sinusitis. It may arise either by direct extension through the sinus wall or, less commonly, as a result of local thrombophlebitis.

\section{Acknowledgements}

The authors wish to express their gratitude to the Departments of Otolaryngology, Head and Neck Surgery, Anatomy and Radiology at the University of Michigan for allowing them access to materials for our study. Also, thanks to Ms Rita Gilliland for manuscipt preparation.

\section{References}

1 Gelladay A.M., Shulman S.T. \& Ayoub E.M. (1978) Periorbital and orbital cellulitis and children. Pediatrics 61, 272-277

2 Weiss A., Friendly D., Eglin K., Chang M. \& GoLD B. (1983) Bacterial periorbital and orbital cellulitis in childhood. Ophthalmology 90, 195-203

3 Hawkins D.B. \& Clark R.W. (1977) Orbital involvement in acute sinusitis. Clin. Pediatr. 16, $464-471$

4 Schramm V.L., Meyers E.N. \& Kennerdell J.S.
(1978) Orbital complications of acute sinusitis: evaluation, management and outcome. Otolaryngol. Head \& Neck Surg. 86, 221-230

5 Harley M.J. \& Geurier T.A. (1978) Orbital cellulitis related to an influenza $A$ virus epidemic. Brit. Med. J. 2, 13-14

6 HarRIS G.J. (1983) Subperiosteal abscess of the orbit. Arch. Ophthalmol. 101, 751-757

7 MONTGOMERY W. (1977) Complications of sinus disease. In Diseases of the Ear, Nose and Throat, 12th edn, ed. J.J. Ballenger, pp 219-226, Lea and Febiger, Philadelphia

8 Clairmont A.A. \& Peri-Lea J.H. (1975) Complications of acute frontal sinusitis. Am. Fam. Phys. 11, 80-84

9 DAwes J.D.K. (197I) Complications of acute and chronic sinusitis. In Scott Brown's Diseases of the Ear Nose and Throat, eds J. Ballantyne \& J. Groves, pp. 265-297, Butterworths, London

10 Gamble R.C. (1983) Acute inflammation in the orbit in children. Arch. Ophthalmol. 10, 483-497

11 Haynes R.E. \& CRamblett H.G. (1967) Acute ethmoiditis: its relationship to orbital cellulitis. Am. J. Dis. Child 114, 26I-267

12 JarretT W.H. \& Gutman F.A. (1969) Occular complications of infection of the paranasal sinuses. Archives Ophthalmol. 81, 683-688

13 Quick C.A. \& Payne E. (1972) Complicated acute sinusitis. Laryngoscope 82, 1248-1263

14 Gans H., Sekula J. \& Wlodyka J. (1974) Treatment of acute orbital complications. Arch Otolaryngol 100, 329-332

15 Brook I., Friedman E.M., Rodriguez W.J. \& Controni M.S. (1966) Complications of sinusitis in children. Pediatrics 66, 568-572

16 Morgan P.R. \& MORRISON W.V. (1980) Complications of frontal and ethmoidal sinusitis. Laryngoscope 90, 661-666.

17 Goldberg F., Berne A.J. \& Oski F.A. (1978) Differentiation of orbital cellulitis from preseptal cellulitis by computed tomography. Pediatrics 62 , 1000-1004

18 Bilaniuk L.J. \& Zimmerman R.A. (1980) Computer assisted tomography: sinus lesions with orbital involvement. Head and Neck Surg. 2, 293-301

19 Watters E.C., Wallar H., Hiles D.A. \& Michaels R.H. (1976) Acute orbital cellulitis. Archives Ophthalmol 94, 785-788

20 AVERY L.B. (1953) The sense organs. In Morris Human Anatomy, ed. J.P. Schaefer, pp. 1152-1153, Blakiston, New York

21 BaSmasion J.V. (1975) Orbital cavity and contents In Grant's Method of Anatomy, 9th edn, p. 500, Williams and Wilkins, Baltimore

22 Batson O.V. (1936) Relationship of the eye to the paranasal sinuses. Arch Ophthalmol 16: 322-323.

23 Chandler J.R., l.angenbrunner D.J. \& Stevens E.R. (1970) The pathogenesis of orbital complications in acute sinusitis. Laryngoscope 80, 1414-1428

24 HAJEK M. (1926) Complications involving the orbit and visual organ. In Pathology and Treatment of the Inflammatory Disease of the Nasal Accessory Sinuses, Vol 2, pp. 578-606, Mosby, St. Louis. 
25 Williamson-Noble F.A. (1954) Diseases of the orbit and its contents secondary to pathological conditions of the nose and paranasal sinuses. Annals Royal Col. Surg. 15, 46-64

26 RitTER F.N. (1973) The maxillary sinus. In The Paranasal Sinuses: Anatomy and Surgical Technique. Mosby, St. Louis

27 FrIED L.A. (1980) Nasal cavity and paranasal sinuses. In Anatomy of the Head, Neck, Face and Jaws, 2nd edn, pp 253-264, Lea and Febiger, Philadelphia.
28 HAJEK M. (1926) Normal anatomy of the frontal sinus. In Pathology and treatment of the Inflammatory Diseases of the Nasal Accessory Sinus, Vol. 2, pp 518-606, Mosby, St Louis

29 DAwes J.D.K. (1961) The management of frontal sinusitis and its complications. J. Laryngol Otol. 75, 297-364

30 Lillie H.T. (1946) Osteomyelitis of the maxilla secondary to suppurative maxillary sinusitis. Annals Otol. Rhinol. Laryngol. 55, 495-507 